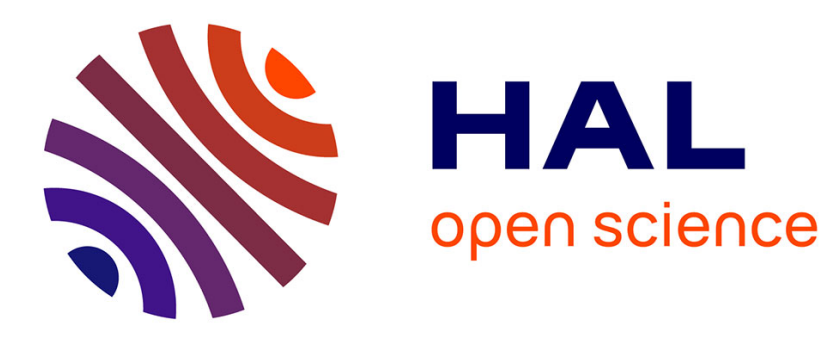

\title{
Structural knowledge learning from maps for supervised land cover/use classification: Application to the monitoring of land cover/use maps in French Guiana
}

Meriam Bayoudh, Emmanuel Roux, Gilles Richard, Richard Nock

\section{- To cite this version:}

Meriam Bayoudh, Emmanuel Roux, Gilles Richard, Richard Nock. Structural knowledge learning from maps for supervised land cover/use classification: Application to the monitoring of land cover/use maps in French Guiana. Computers \& Geosciences, 2015, 76, pp.31-40. 10.1016/j.cageo.2014.08.013 . hal-01369822

\section{HAL Id: hal-01369822 \\ https://hal.science/hal-01369822}

Submitted on 21 Sep 2016

HAL is a multi-disciplinary open access archive for the deposit and dissemination of scientific research documents, whether they are published or not. The documents may come from teaching and research institutions in France or abroad, or from public or private research centers.
L'archive ouverte pluridisciplinaire $\mathbf{H A L}$, est destinée au dépôt et à la diffusion de documents scientifiques de niveau recherche, publiés ou non, émanant des établissements d'enseignement et de recherche français ou étrangers, des laboratoires publics ou privés. 


\title{
Structural knowledge learning from maps for supervised land cover/use classification: Application to the monitoring of land cover/use maps in French Guiana
}

\author{
Meriam Bayoudha,c,*, Emmanuel Roux ${ }^{\mathrm{a}}$, Gilles Richard ${ }^{\mathrm{b}}$, Richard Nock ${ }^{\mathrm{c}, \mathrm{d}}$ \\ ${ }^{a}$ ESPACE-DEV, UMR228 IRD/UMII/UR/UAG, Institut de Recherche pour le \\ Développement \\ ${ }^{b}$ Institut de Recherche en Informatique de Toulouse (IRIT), UMR5505 \\ CNRS/INPT/UPS/UT1/UTM, Toulouse, France \\ ${ }^{c}$ Université des Antilles et de la Guyane, France \\ ${ }^{d}$ Centre d'Etude et de Recherche en Economie, Gestion, Modélisation et Informatique \\ Appliquée (CEREGMIA), Martinique, France
}

\section{Abstract}

The number of satellites and sensors devoted to earth observation has become increasingly elevated, delivering extensive data, especially images. At the same time, the access to such data and the tools needed to process them has considerably improved. In the presence of such data flow, we need automatic image interpretation methods, especially when it comes to the monitoring and prediction of environmental and societal changes in highly dynamic socio-environmental contexts. This could be accomplished via artificial intelligence.

*Corresponding author. Maison de la Télédétection, 500 rue Jean-François Breton, 34093 Montpellier Cedex 5, France. Tel: +33 (0)46791 7260

Email addresses: meriam.bayoudh@ird.fr (Meriam Bayoudh ), emmanuel.roux@ird.fr (Emmanuel Roux), richard@irit.fr (Gilles Richard), Richard.Nock@martinique.univ-ag.fr (Richard Nock) 
The concept described here relies on the induction of classification rules that explicitly take into account structural knowledge, using Aleph, an Inductive Logic Programming (ILP) system, combined with a multi-class classification procedure. This methodology was used to monitor changes in land cover/use of the French Guiana coastline. One hundred and fifty-eight classification rules were induced from 3 diachronic land cover/use maps including 38 classes. These rules were expressed in first order logic language, which makes them easily understandable by non-experts. A ten-fold crossvalidation gave significant average values of $84.62 \%, 99.57 \%$ and $77.22 \%$ for classification accuracy, specificity and sensitivity, respectively. Our methodology could be beneficial to automatically classify new objects and to facilitate object-based classification procedures.

Keywords: Supervised classification, Machine learning, Inductive Logic Programming (ILP), Geographic Information System, Land cover map.

\section{Introduction}

The availability of remotely sensed Earth observation data, taken from aircrafts (including drones) and satellites, is constantly increasing. This obviously comes from the increasing number of Earth observation satellites and sensors. In fact, a recent report (Zaiche and Smith, 2011) estimates that the number of satellite launches will be $50 \%$ higher during the next ten years, when compared to the last decade. In particular, 200 governmental Earth observation satellites will be launched during that period. At the same time, as an increasing number of countries and/or organizations distribute remotely sensed data for free, the evolution in data distribution 
and use policies contributes to the use of huge volumes of data. Thus, data processing and interpretation have become a serious challenge for engineers and researchers. Therefore, classical procedures cannot continue to be used, and new approaches are needed to automatically update the land cover/use maps that provide essential information to decision makers.

In this context, several studies have formally represented and introduced expert knowledge for automatic image classification and interpretation. For instance, Suzuki et al. (2001) built a system for satellite image classification based on expert knowledge. More recently, Forestier et al. (2012) built a knowledge-base of urban objects, allowing the interpretation of high spatial resolution images in order to assist urban planner with mapping tasks. Recent studies devoted to expert knowledge formalization for automatic image interpretation have been directed towards ontologies. Hudelot et al. (2008) proposed an ontology of spatial relations to guide medical image interpretation, which is then enriched by fuzzy representations of concepts. Within the remote sensing framework, both Durand et al. (2007) and Andres et al. (2012) propose ontology-based automatic procedures for image processing.

A complementary approach to expert knowledge formalization is knowledge extraction from data. Such approach is utilized by all existing supervised image classification procedures, which first require a learning phase with delimitation and labeling (allocation to a class) of regions in the image. However, most methods consider only pixel information within such regions to separate and characterize the different classes. Structural aspects, i.e., information arrangement in space, are essentially taken into account by computing textural indexes within the same regions. To our knowledge, there is no op- 
erative tool that provides general and efficient classification rules exploiting structural knowledge at a higher semantic level, particularly at the object level within the object-oriented image analysis (Blaschke, 2010), when such knowledge is more robust and expressive than at the pixel level.

Automatically learning such structural knowledge within the supervised framework, however, requires the delimitation and labeling of many more regions than with pixel-based approaches, and would consequently entails important expert efforts. One solution would be to take advantage of existing maps resulting from different types of expertise already acquired (e.g., expertise in remote sensing, image processing, environment, ecology, etc.).

Thus far, very few studies have proposed to learn structural knowledge from maps.

Malerba et al. (2003) implemented INductive GEographic iNformation System (INGENS) to assist with topographic map interpretation. INGENS consists of a prototypical extended Geographic Information System (GIS) with inductive learning capabilities. GIS classical functionalities are used to extract relevant concepts and features from spatial database, and the integrated inductive system allows finding rules to automatically recognize complex geographical contexts that are defined by the presence of specific geographical objects and their spatial arrangement in predefined spatial windows (cells). It is devoted to support map interpretation and geographical information retrieval by enriching geographical queries, but not to automatic classification in the context of large datasets. In fact, such automatic procedures require a quantitative evaluation that has not been performed with INGENS. Vaz et al. (2007) use an Inductive Logic system called APRIL (Fonseca et al., 
2006) to learn classification rules from both a detailed map provided by botanists and CORINE Land Cover (CLC) maps of the same zone. Such rules are intended to automatically disaggregate CLC map information that is considered too generic within the application framework. Here again, the precision of the system is not provided.

Inductive learning of structural features from maps has been applied to the prediction of particular events that partially depend on landscape characteristics. Vaz et al. (2010) propose a system that predicts wildfires from information on past fires and from compositional and structural features of the land use. However, the performance of the predictions, estimated by a 10-fold cross validation, does not seem to allow operational use.

Finally, Chelghoum et al. (2006) automatically transformed spatial relation information stored in multi-tables into first-order logic, and used S-TILDE (Spatial Top-down Induction Logical DEcision tree) to induce classification rules. They applied their method for spatial prediction of shellfish contamination in the Thau lagoon. Their work considered only the binary classification problem.

In such applicative and scientific contexts, we report here a method for structural and symbolic knowledge extraction from land use/cover maps and complementary geographic information layers, combined with a multi-class classification approach. Our work does not deal with the delimitation of regions (or segments) from images, but with the labeling of previously defined image regions. Methods intended to image region delimitation, including segmentation methods, are therefore beyond the scope of this study. In this study we chose the Inductive Logic Programming framework (ILP) (Mug- 
gleton, 1991) for the learning task, and a multi-class classification procedure developed by Abudawood and Flach (2011) within the ILP framework, i.e., the Multi-class Rule Set Intersection (MRSI). This methodology was tested to update land cover/use maps of the French Guiana coastline, and the resulting classification system was thoroughly evaluated from qualitative and quantitative points of view through a ten-fold cross-validation.

Our paper is organized as follows: the general methodology is explained, by presenting the ILP approach, the geographic information extraction and coding, the multi-class classification technique and the evaluation procedures. Then, the application to land/use maps updating is described, by detailing the exploited dataset and the adaptation of the general methodology. The next section presents the results by qualifying the induced rules and providing prediction quantitative scores. We then discuss our results and a general conclusion is given about the proposed approach.

\section{Materials and Methods}

\subsection{Inductive Logic Programming}

Inductive Logic Programming (ILP) (Muggleton, 1991) is a search field that combines machine learning and logic programming. It is a technique for learning a general theory $H$ from a background knowledge $B$ and examples $E$ within a framework provided by clausal logic.

ILP can model complex problems and has been used in several fields such as chemistry (Blockeel et al., 2004), biology, physics, medicine (Luu et al., 2012; Fromont et al., 2005), ecology and bio-informatics (Santos et al., 2012; Lavrac and Dzeroski, 1994; Srinivasan et al., 1996). It has, also, been applied 
to chess (Goodacre, 1996) and to test the quality of river water (Cordier, 2005). Very few studies have applied this method to geographical data, as already discussed in the introduction (Malerba et al., 2003; Vaz et al., 2007, 2010; Chelghoum et al., 2006).

ILP is defined as follows (Lavrac and Dzeroski, 1994):

Given:

- A description language $L$.

- Background knowledge $B$, expressed under Horn clauses (a subset of general first order logic formula, expressed using $L$, describing the existing knowledge and constraints on the target concept, i.e., in our case, the allocation to a given land cover/use class;

- A set of examples $E$, divided into two subsets, $E^{+}$and $E^{-}$, which represent the sets of positive and negative examples, respectively;

Find a "theory" $H$, i.e., a set of formula using the description language $L$ that covers positive examples $E^{+}$, but does not cover (or in a controlled way) the negative examples $E^{-}$.

We chose the ILP engine Aleph (Srinivasan, 2007). It is an open source ILP system, written in Prolog, using top-down search and based on inverse entailment (Muggleton, 1995).

\subsection{Geographic information extraction and coding}

Each patch of land use/cover map is referred to as object and defines the elementary geographical entity to which the reasoning will be applied. Objects are used to define the examples for the learning and test phases. 
Objects are described using predicates characterizing their intrinsic (class, area, fractal dimension, compactness, perimeter) and relational features (adjacency, inclusion, relative positions in latitudinal and longitudinal directions) ( $c f$. Table 1). The choice of such predicates is essentially based on $a$ priori knowledge of the authors on the discriminating features of the spatial objects constituting land cover/use maps.

Inductive Logic Programming being adapted to symbolic information, discretization of the numeric variables is performed, and the information recoded as follows: for any numeric variable $V$, the $10^{\text {th }}, 20^{\text {th }}, \ldots, 90^{\text {th }}$ percentiles of the empirical distribution of $V$, denoted $p_{k}(k \in[1,9])$, are computed. Then, for every $p_{k}$, two predicates were defined to indicate if an observed value $X$ for $V$ is lower or higher than $p_{k}$. For instance, the observed numeric value $X$, corresponding to the area of the object $O$, is recoded, for $p_{k}$, as follows:

$$
\begin{aligned}
& \operatorname{area\_ symb}\left(O, I_{k}\right) \text { : - area_num }(O, X), \quad X \leq p_{k} \text {. } \\
& \text { or area_symb }\left(O, S_{k}\right): \text { - area_num }(O, X), \quad X>p_{k} .
\end{aligned}
$$

with $I_{k}$ and $S_{k}$ as the intervals [-inf, $\left.p_{k}\right]$ and $\left.] p_{k},+\inf \right]$, respectively.

Eventually, the latitude and longitude values were used to characterize the relative positions of the object pairs ( $c f$. Table 1$)$. 
Table 1: Predicates used for object characterization. Asterisk indicates that the predicate is not used in the rule premises.

\begin{tabular}{|c|c|}
\hline Predicates & Description \\
\hline object $(O)$ & Declaration of the object $O$ \\
\hline $\operatorname{class}(O$, class_label) & $\begin{array}{l}\text { The object } O \text { belongs to the } \\
\text { class class_label }\end{array}$ \\
\hline adjacent $(O 1, O 2)$ & $O 1$ and $O 2$ are two adjacent objects \\
\hline included $(O 1, O 2)$ & $O 2$ is included in $O 1$ \\
\hline contains $(O, E)$ & $\begin{array}{l}O \text { contains the entity } E \\
(\text { e.g. } E \in\{\text { River }, \text { Road, Building }, \ldots\})\end{array}$ \\
\hline area_num $(O, X) *$ & \multirow{4}{*}{$\begin{array}{l}X \text { is the area }\left(\mathrm{m}^{2}\right), \text { the compactness } \\
\text { value, the fractal dimension } \\
\text { and the perimeter }(\mathrm{m}) \text { of the object } O \text {, } \\
\text { respectively, with }(X \in \Re)\end{array}$} \\
\hline compactness_num $(O, X) *$ & \\
\hline fract_dim_num $(O, X) *$ & \\
\hline perimeter_num $(O, X) *$ & \\
\hline $\operatorname{area} \_\operatorname{symb}\left(O, I_{k}^{\text {area }}\right.$ or $\left.S_{k}^{\text {area }}\right)$ & \multirow{4}{*}{$\begin{array}{l}\text { Recoding of the numeric } \\
\text { variables according to the } \\
\text { percentiles (see text for details) }\end{array}$} \\
\hline compactness_symb $\left(O, I_{k}^{\text {comp }}\right.$ or $\left.S_{k}^{\text {comp }}\right)$ & \\
\hline fract_dim_symb $\left(O, I_{k}^{d f}\right.$ or $\left.S_{k}^{d f}\right)$ & \\
\hline perimeter_symb $\left(O, I_{k}^{p e r}\right.$ or $\left.S_{k}^{p e r}\right)$ & \\
\hline $\operatorname{lat}(O, X) *$ & \multirow{2}{*}{$\begin{array}{l}X \text { is the latitude and } \\
\text { longitude of } O \text {, respectively, } \\
(X \in \Re)\end{array}$} \\
\hline long $(O, X) *$ & \\
\hline $\begin{array}{l}\operatorname{north}(O 1, O 2):- \\
\operatorname{lat}(O 1, \mathrm{~A}), \operatorname{lat}(O 2, \mathrm{~B}), \mathrm{A}>\mathrm{B} .\end{array}$ & \multirow{4}{*}{$\begin{array}{l}O 1 \text { is located north, } \\
\text { south, east and } \\
\text { west of } O 2 \text {, respectively. }\end{array}$} \\
\hline $\begin{array}{l}\text { south }(O 1, O 2):- \\
\operatorname{lat}(O 1, \mathrm{~A}), \operatorname{lat}(O 2, \mathrm{~B}), \mathrm{A} \leq \mathrm{B} .\end{array}$ & \\
\hline $\begin{array}{l}\text { east }(O 1, O 2):- \\
\text { long }(O 1, \mathrm{~A}) \text {, long }(O 2, \mathrm{~B}), \mathrm{A}>\mathrm{B} .\end{array}$ & \\
\hline $\begin{array}{l}\text { West }(O 1, O 2):- \\
\text { long }(O 1, \mathrm{~A}) \text {, long }(O 2, \mathrm{~B}), \mathrm{A} \leq \mathrm{B} \text {. }\end{array}$ & \\
\hline
\end{tabular}




\subsection{Rule induction: one-vs-rest approach}

Once the information is extracted and coded according to the above method, the classification rules are induced by the inductive system Aleph. When applying ILP within the multi-class framework, i.e., in the case of more than two classes (each object belonging to only one class), the one-vs-rest approach is a commonly used approach (Abudawood and Flach, 2011). Such method consists in generating as many classifiers as classes, by defining the positive and negative example sets for each class $c$ as follows:

$$
\left\{\begin{array}{l}
E^{+}=\{O / \operatorname{classe}(O, c)\} \\
E^{-}=\{O / \operatorname{classe}(O, \bar{c})\}
\end{array}\right.
$$

and by running Aleph with such example sets, for each class $c$.

\subsection{Multi-class framework}

Considering the previously described one-vs-rest approach results in inducing as many classifiers as classes. Considering the classifiers independently of one another, one or several classes can be predicted when a new object is to be classified. Abudawood and Flach (2011) proposed several solutions to handle multi-class problems for ILP. Among them, the Multiclass Rule Set Intersection (MRSI) method gave the highest accuracies and Areas Under the ROC Curve (AUC) when taking multi-class data sets into account (Abudawood and Flach, 2011). The principle of the MRSI method is: i) the theories induced for each class are gathered in an unique rule set; ii) for each rule $i$, the set of covered examples by the rule, $C_{i}$, is stored; iii) a default rule is formed that concludes to the majority class of the uncovered examples; iv) for an unseen object $O$, the intersection of the sets of examples 
covered by the fired rules is computed $\left(I=\cap C_{i} \mid r_{i}\right.$ is fired) and, finally; v) the predicted class $\hat{c}$ is the majority class in the set $I$, i.e., the more probable class given to the new object $O$, with an empirical probability $p(c \mid O)$.

\subsection{Prediction evaluation}

Overall accuracy, sensitivity, specificity and Kappa index are computed based on a 10-fold stratified cross-validation procedure.

For each class $C_{i}(i \in[1, n])$, the set of positive examples $E_{i}$ is randomly divided in ten subsets $E_{i, f}(f \in[1,10])$. If a class $j$ is associated with $p$ positive examples, with $p<10$, then $E_{i, f>p}=\emptyset$. Then the $f^{t h}$ learning set for the $i^{\text {th }}$ class is defined as follows:

$$
\left\{\begin{array}{l}
E_{i, f}^{+}=\cup_{l=1, \ldots, 10 ; l \neq f} E_{i, l} \\
E_{i, f}^{-}=\cup_{j=1, \ldots, n ; j \neq i}\left\{\cup_{l=1, \ldots, 10 \quad l \neq f} E_{j, l}\right\}
\end{array}\right.
$$

In the multi-class classification framework, one test set $T_{f}$ has to be defined for each fold $f$. Such test set is consequently defined as follows:

$$
T_{f}=\cup_{i=1, \ldots, n} E_{i, f}
$$

Overall accuracy, sensitivity, specificity and Kappa index values are computed for each test set, then averaged. The formulas of these measures are given hereafter.

The multi-class classification procedure previously described permits to compute the multi-class contingency table (see Table 2) for each test set, and to obtain the overall accuracy as follows (Abudawood and Flach, 2011):

$$
\text { Overall Accuracy }=\sum_{i=1}^{n} \frac{T P^{(i)}}{E}
$$


where $n$ is the number of classes, $T P^{(i)}$ the number of true positives for the class $i$, and $E$ the total number of test examples.

Table 2: Contingency table with notations (TP: True Positive; TN: True Negative; FP: False Positive; FN: False Negative) for the class $i$ only. (Adapted from Abudawood and Flach (2011))

\begin{tabular}{cc|ccccccc|c} 
& & \multicolumn{7}{|c}{ Predicted } \\
& & $C_{1}$ & $\ldots$ & $C_{i-1}$ & $C_{i}$ & $C_{i+1}$ & $\ldots$ & $C_{n}$ & Total \\
\hline \multirow{4}{*}{ Actual } & $C_{1}$ & $T N_{1}^{(i)}$ & $\ldots$ & $\ldots$ & $F P_{1}^{(i)}$ & $\ldots$ & $\ldots$ & $\ldots$ & $E_{1}$ \\
& $\ldots$ & $\ldots$ & $\ldots$ & $\ldots$ & $\ldots$ & $\ldots$ & $\ldots$ & $\ldots$ & $\ldots$ \\
& $\ldots$ & $\ldots$ & $\ldots$ & $T N_{i-1}^{(i)}$ & $F P_{i-1}^{(i)}$ & $\ldots$ & $\ldots$ & $\ldots$ & $E_{i-1}$ \\
& $\ldots$ & $F N_{1}^{(i)}$ & $\ldots$ & $F N_{i-1}^{(i)}$ & $T P^{(i)}$ & $F N_{i+1}^{(i)}$ & $\ldots$ & $F N_{n}^{(i)}$ & $E_{i}$ \\
& $\ldots$ & $\ldots$ & $\ldots$ & $F P_{i+1}^{(i)}$ & $T N_{i+1}^{(i)}$ & $\ldots$ & $\ldots$ & $E_{i+1}$ \\
& $\ldots$ & $\ldots$ & $\ldots$ & $\ldots$ & $\ldots$ & $\ldots$ & $\ldots$ & $\ldots$ & $\ldots$ \\
& $C_{n}$ & $\ldots$ & $\ldots$ & $\ldots$ & $F P_{n}^{(i)}$ & $\ldots$ & $\ldots$ & $T N_{n}^{(i)}$ & $E_{n}$ \\
\hline & Total & $\hat{E}_{1}$ & $\ldots$ & $\hat{E}_{i-1}$ & $\hat{E}_{i}$ & $\hat{E}_{i+1}$ & $\ldots$ & $\hat{E}_{n}$ & $E$
\end{tabular}

For each class $i$, the sensitivity, i.e. the ability of the classifier to successfully classified positive examples, is computed as:

$$
\text { Sensitivity }^{(i)}=\frac{T P^{(i)}}{T P^{(i)}+\sum_{j=1, j \neq i}^{n} F N_{j}^{(i)}}=\frac{T P^{(i)}}{E_{i}}
$$

where $F N_{j}^{(i)}$ is the number of false negatives for the class $i$ wrongly associated to the class $j$.

The specificity, i.e. the ability of the classifier to successfully classified negative examples, is computed as: 


$$
\text { Specificity }^{(i)}=\frac{\sum_{j=1, j \neq i}^{n} T N_{j}^{(i)}}{\sum_{j=1, j \neq i}^{n} T N_{j}^{(i)}+\sum_{j=1, j \neq i}^{n} F P_{j}^{(i)}}
$$

${ }_{217}$ where $T N_{j}^{(i)}$ is the number of true negatives for the class $i$ successfully

220

attributed to the class $j$ and $F P_{j}^{(i)}$ the number of false positives for the class $i$ that actually belong to the class $j$.

Finally, the Kappa index is computed for each test set. Cohen's Kappa (Cohen, 1960) provides a statistical measure of inter-agreement for qualitative items. In the framework of classification, it measures the degree of agreement between predicted and actual classes. Kappa index is defined as follows:

$$
\text { kappa }=\frac{P(A)-P(H)}{1-P(H)}
$$

With $P(A)$ corresponding to the observed proportion of agreement between two classifications, and $P(H)$ the estimated proportion of agreement expected by chance.

\section{Application to the update of the land cover/use maps of the French Guiana coastline}

The concepts and methods previously defined were applied to an actual geographic situation. The French Guiana territory is subject to intense anthropogenic and natural dynamics (Anthony et al., 2010): cyclic coastal erosion and accretion, notably due to the transport of sediments from the Amazon River by oceanic currents; and expansion of urban, peri-urban, agri- 
cultural areas. In this context, it is essential to develop automated methods for monitoring the land cover/use of the French Guiana territory. In particular, the large amount of available aerial photographs and satellite images is a critical source of materials that should be better exploited. If the delimitation of the geographical objects of interest does not require a high level of expertise and can be performed by operators, allocating these objects to land cover/use classes appears far more complex and subjective. In fact, despite efforts made to formalize and standardize the classification procedures, such allocating task requires a deep knowledge of the different types of land cover/use, both in the imaging and applicative domains. Consequently, the learning and classification methods previously presented were applied to automatically perform the labeling task and update the land cover/use maps of the French Guiana coastline.

\subsection{Dataset}

We took advantage of a series of three land cover/use maps of the French Guiana coastline for 2001, 2005 and 2008. The classification nomenclature is based on the CORINE Land Cover (CLC) European nomenclature, which is adapted to the Amazonian context by the addition of 15 classes, 9 of them corresponding to different types of forests, and consists of three nested levels where the most detailed (level III) is composed of 39 classes.

The maps were produced by the French National Office of Forests (Office National des Forêts; ONF) by photo-interpretation of the BD-Ortho ${ }^{\circledR}$ aerial photographs of the French National Geographic Institute (Institut Géographique National: IGN) for 2001 and 2005. Air photographs had a 50-cm spatial resolution. The land cover/use map for 2008 was updated using 2.5- 
261 meter spatial resolution satellite images acquired by the SPOT 5 satellite 262 and obtained through the SEAS-Guyane ${ }^{1}$ project.

\footnotetext{
${ }^{1}$ https://www.seas-guyane.org
} 


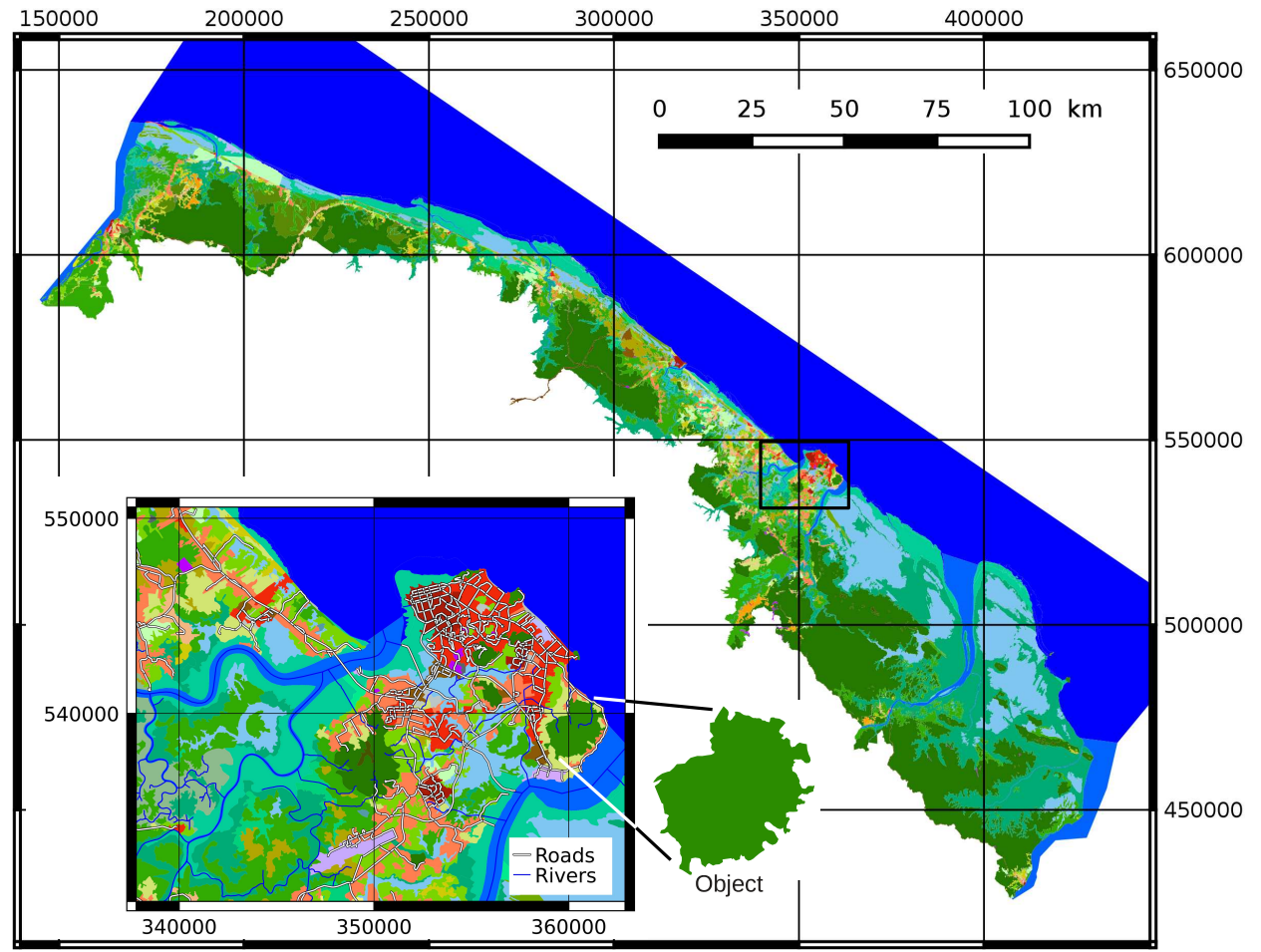

\begin{tabular}{l|l}
\hline Ocean & Territories occupied mainly by agriculture with presence of vegetation \\
\hline River & Fragmented/complex cropping systems (slash and burn) \\
Natural water surface & Forest on sandy cord \\
\hline Pisciculture and other basins & Forest of the old coastal plain \\
\hline Artificial green space & Low forest on white sand \\
\hline Continuous urban area & Coastal forest on rocks \\
Discontinuous urban area & High moist evergreen forest on hills and plateaus with ferralitic soil \\
Isolated building & Low moist evergreen forest on hills and plateaus with ferralitic soil \\
\hline Multidisciplinary habitat & Marshy or flooded forest \\
\hline Industrial or commercial area & Mangrove \\
\hline Road network & Forest plantation \\
\hline Port & Dry savannah \\
\hline Airport & Flooded savannah \\
\hline Material extraction & Beach, mud bank, dune \\
Garbage dump & Bare rocks, rock savannah \\
Construction site & Degraded forest \\
\hline Arable land out of irrigation & Degraded marshy or flooded forest \\
\hline Paddy field & Forest and shrubs in mutation \\
\hline Fruit orchards & Interior marsh and wooded swamp \\
Prairies & Riparian swamp \\
\hline
\end{tabular}

Figure 1: Land cover/use map and complementary geographic information layers (inset) used in this article (geographic coordinate system: WGS84 / UTM zone 22N). Sources: French National Office of Forests (Office National des Forêts; ONF); French National Geographic Institute (Institut Géographique National: IGN); French Ministry in charge of the environment; Regional Direction of the Environment (DIREN) of French Guiana ; French National Agency for Water and Aquatic Environments (ONEMA). See text for details. 
Two complementary geographic information layers were used (see Figure 1): the road network, provided by the BD-Carto $\AA$ database of the IGN, and the river network provided by the BD-Carthage ${ }^{\circledR}$ database of the French Ministry in charge of the Environment and of the IGN, produced in 2009 for French Guiana by the Regional Direction of the Environment (DIREN) of French Guiana and the French National Agency for Water and Aquatic Environments (ONEMA).

\subsection{Data pre-processing: definition of the map objects}

Firstly, we completed the initial land cover/use classification by adding three more classes: Ocean, River and Unknown. The first two classes contribute significantly to the structure of the environment in the French Guiana territory, and the Unknown class explicitly takes into account the fact that information was not available for some areas in 2001 and/or 2005. However, we did not induce any rules to predict membership to these three classes. Finally, the class Paddy field was not considered as it was under-represented in the maps (only 2 positive examples). Thus 38 land cover/use classes were considered (see Tables 3, 4 and 5 for the class list).

In this study, we follow the land cover/use class of the objects in time. We do not explicitly follow the object delimitations, which is a much more complex task. In fact, by taking into account the information provided by three original maps, object boundaries can change in time: an object can be splitted into two or more objects belonging to different classes (see for instance object $s_{13}$ in figure 2), creating new object(s); an object can result from the merging of several objects, making one or several objects disappear. We handled such situations by generating objects with invariant boundaries in time and 
related to an unique class for each year. Practically, we produced a synthetic map by concatenating the information contained in the three original maps, by means of the "union" GIS operator, as schematically shown in Figure 2. The elementary geographical entities of the resulting map are referred to as objects thereafter, and contribute to define the examples in the ILP process.

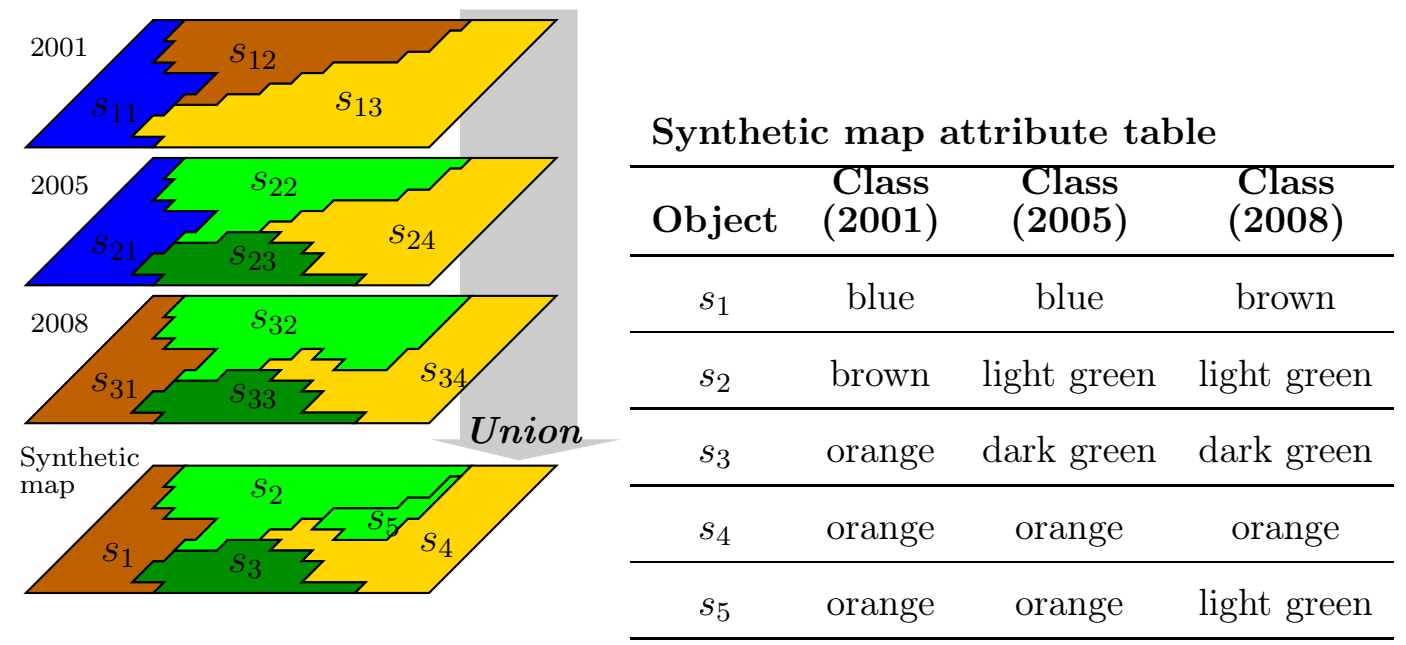

Figure 2: Illustrative example explaining the definition of a synthetic map that combines the information from the three initial maps.

\subsection{Information coding}

Target predicates (i.e., concepts to be learned) were defined as the land cover/use classes to which the objects of the synthetic map belonged in 2008, considered as the reference year $y_{0}$.

Given the diachronic characteristics of the data, 3 predicates were defined to indicate the class of an object as a function of the time: class_ $y_{0}(O$, class_name), class_ $y_{-3}(O$, class_name $)$ and class_ $y_{-6}(O$, class_name $)$, indicating the land cover/use class of the object $O$ for the years $y_{0}, y_{-3}$ and $y_{-6}$, respec- 
tively, i.e, for 2008, 2005 and 2001. It is worth noting that from a relative point of view, the year 2001, seven years prior 2008, is assumed to actually correspond to the sixth year before the reference year $y_{0}$. In fact, we can assume marginal changes between 2001 and 2002. However, this assumption has also a practical justification as it permits to consider the updating of the land cover/use information every three years based on the maps established three and six years before.

Given the complementary information layers used in our test, the predicate contain $(O, X)$ referred to rivers and roads $(X \in\{$ river, road $\})$ (see Table 1).

All object features were extracted using the free and open source GRASS Geographic Information System (GRASS Development Team, 1999-2012).

\subsection{Rule induction: Aleph parametrization}

In Aleph, the accuracy of the candidate clauses was set to 0.7 , considered as a good compromise between precision and generalization requirements. Such accuracy is defined as $p /(p+n)$, where $p$ and $n$ are the numbers of positive and negative examples, respectively, which are covered by the clause. Consequently, it differs from the overall accuracy defined in section 2.5, which evaluates the global prediction accuracy of the classification system, based on the whole induced rule set.

The maximum premise length was set to 5 literals, such number of conditions in a conjunction being practically considered as the limit for easy comprehension (Michalski, 1983). 


\section{Results}

\subsection{Set of induced rules}

The induction process returned 158 classification rules for the 38 land cover/use classes. However, the distribution among land cover/use classes is not homogeneous (see Tables 3 to 5). For instance, we obtained 23 rules for the class Forest of the old coastal plain whilst we had just one rule for the Riparian swamp class. Rules cover from 2 to 692 positive examples while the number of covered negative examples varied from 0 to 99 .

Three examples of induced rules are shown below, with the number of positive (Pos cover) and negative (Neg cover) examples covered by the rule, and the total number of positive examples for the considered target predicate (Total pos. ex.) in brackets.

(1) $($ Pos cover $=472 ;$ Neg cover $=88 ;$ Total pos. ex. = 552) class_y (A, Multidisciplinary habitat) :- area_symb(A, $\leq 165567)$,

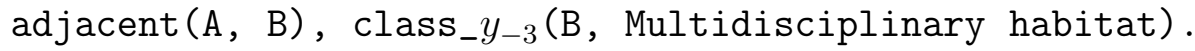

(2) $($ Pos cover $=2$ Neg cover $=0$ Total pos. ex. = 40) class_y (A, Industrial or commercial area) :- $\operatorname{adjacent}(A, B)$, class_y-6 (B, Construction sites), area_symb(A, $\leq 10831)$.

(3) $($ Pos cover $=3 \mathrm{Neg}$ cover $=0$ Total pos. ex. = 166) class_y $y_{0}$ (A, Discontinuous urban area) :- class_y-6 (A, Construction sites), area_symb(A, $\leq 76202)$, $\operatorname{area} \operatorname{symb}(\mathrm{A},>10831)$.

Rule (1) covers 472 positive examples for a total of 552 objects actually belonging to the class of interest $(85.5 \%)$ and 88 negative examples. It indicates that an object will belong to the Multidisciplinary habitat class if 
its area is less than or equal to $165567 \mathrm{~m}^{2}$ and is adjacent to an object belonging to the same class three years before. Rule (2) indicates that an object will belong to the Industrial or commercial area class if its area is less than or equal to $10831 \mathrm{~m}^{2}$ and is adjacent to an object belonging to the class Construction sites 6 years before. Rule (3) indicates that an object will belong to the Discontinuous urban area class if its area, in $\mathrm{m}^{2}$, belongs to the interval ]10831,76202] and if it belonged to the class Construction sites 6 years before. By considering such rules for the characterization of the territory dynamics, the first rule illustrates the extension dynamics of the natural areas whereas the second and the third rules describe the extension dynamics of the anthropogenic areas.

\subsection{Prediction evaluation}

Tables 3 to 5 report the sensitivity results for each land cover/use class in the one-vs-rest framework by considering each classifier independently, and correspond to sensitivity values that fall in the intervals ]0\%,50\%], ]50\%, 80\%] and $] 80 \%, 100 \%$ ], respectively. Among the 38 land cover/use classes, only 5 classes $(13.1 \%)$ were associated with sensitivity values under $50 \%$. Twelve classes $(31.6 \%)$ had sensitivity values between $50 \%$ and $80 \%$, and 21 classes $(55.3 \%)$ had the highest sensitivity values (greater than $80 \%$ ).

All classifiers were $100 \%$ specific, except for one related to the class Forest and shrubs in mutation, which had a specificity of $83.1 \%$. 
Table 3: Averaged sensitivities obtained with 10-fold cross validation, for land cover/use classes associated with "low" sensitivity values (lower than 50\%), total number of positive examples and number of induced rules for each class, by taking into account the whole dataset as learning set. (The nomenclature is based on the CORINE Land Cover (CLC) European Nomenclature with three nested levels. We applied our method to the most detailed level (level III). The nomenclature levels I and II are indicated for facilitate results interpretation only.)

\begin{tabular}{|c|c|c|c|c|c|c|}
\hline 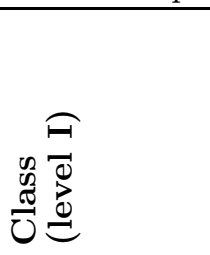 & 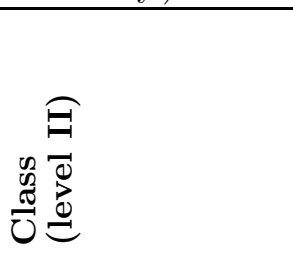 & 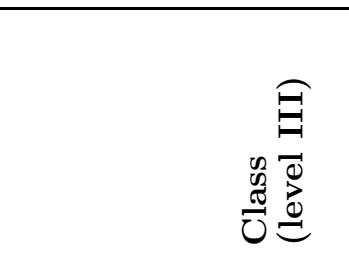 & & 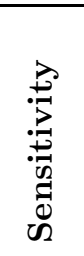 & 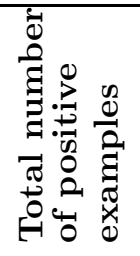 & 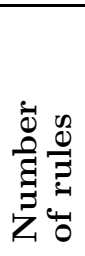 \\
\hline \multirow{2}{*}{$\begin{array}{l}\text { Forest and } \\
\text { semi-natural } \\
\text { area }\end{array}$} & $\begin{array}{l}\text { Open space with } \\
\text { some/no } \\
\text { vegetation }\end{array}$ & $\begin{array}{l}\text { beach, mud } \\
\text { bank, dune }\end{array}$ & & 5.0 & 15 & 1 \\
\hline & Forest & $\begin{array}{l}\text { Moist evergreen } \\
\text { forest of the main- } \\
\text { land coastal plain }\end{array}$ & $\begin{array}{l}\text { Low forest } \\
\text { on } \\
\text { white sand }\end{array}$ & 41.7 & 24 & 1 \\
\hline \multirow{2}{*}{$\begin{array}{l}\text { Artificial } \\
\text { Territories }\end{array}$} & $\begin{array}{l}\text { Mine, garbage } \\
\text { dump or }\end{array}$ & Garbage dump & & 25.0 & 15 & 1 \\
\hline & construction sites & Construction sites & & 30.1 & 97 & 6 \\
\hline $\begin{array}{l}\text { Agricultural } \\
\text { Territories }\end{array}$ & $\begin{array}{l}\text { Heterogeneous } \\
\text { agricultural areas }\end{array}$ & $\begin{array}{l}\text { Territories occupied } \\
\text { mainly by agriculture } \\
\text { with presence } \\
\text { of vegetation }\end{array}$ & & 41.1 & 112 & 3 \\
\hline
\end{tabular}


Table 4: Averaged sensitivities obtained with 10-fold cross validation, for land cover/use classes associated with "medium" sensitivity values (between $50 \%$ and 80\%), total number of positive examples and number of induced rules for each class, by taking into account the whole dataset as learning set.

\begin{tabular}{|c|c|c|c|c|c|c|}
\hline 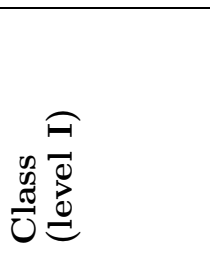 & 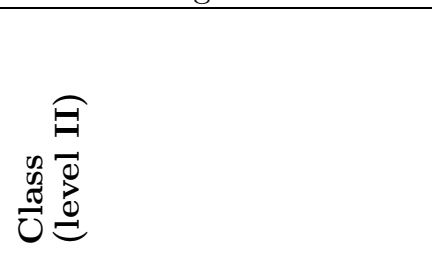 & 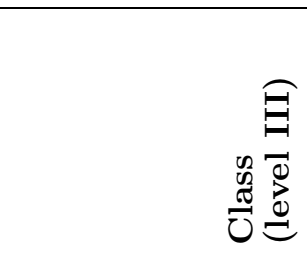 & & 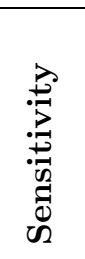 & 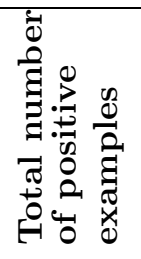 & 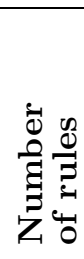 \\
\hline \multirow{5}{*}{$\begin{array}{l}\text { Artificial } \\
\text { Territories }\end{array}$} & \multirow[t]{3}{*}{ Industrial zone } & $\begin{array}{l}\text { Industrial or } \\
\text { commercial area }\end{array}$ & & 65.0 & 40 & 2 \\
\hline & & Road network & & 56.9 & 84 & 3 \\
\hline & & Port & & 80.0 & 5 & 1 \\
\hline & $\begin{array}{l}\text { Mine, garbage } \\
\text { dump or construction sites }\end{array}$ & Material extraction & & 63.5 & 137 & 5 \\
\hline & Artificial green space & & & 75.0 & 8 & 1 \\
\hline \multirow{2}{*}{$\begin{array}{l}\text { Agricultural } \\
\text { Territories }\end{array}$} & Prairies & Prairies & & 67.9 & 243 & 3 \\
\hline & Arable land & $\begin{array}{l}\text { Arable land out } \\
\text { of irrigation }\end{array}$ & & 70.0 & 12 & 1 \\
\hline \multirow{5}{*}{$\begin{array}{l}\text { Forest and } \\
\text { semi-natural } \\
\text { area }\end{array}$} & $\begin{array}{l}\text { Degraded natural } \\
\text { environment }\end{array}$ & Degraded forest & & 60.3 & 483 & 11 \\
\hline & \multirow[t]{3}{*}{ Forest } & $\begin{array}{l}\text { Moist evergreen } \\
\text { forest of the } \\
\text { mainland coastal } \\
\text { plain }\end{array}$ & $\begin{array}{l}\text { Coastal } \\
\text { forest } \\
\text { on rocks }\end{array}$ & 70.0 & 14 & 3 \\
\hline & & & $\begin{array}{l}\text { Forest of } \\
\text { the old } \\
\text { coastal } \\
\text { plain }\end{array}$ & 79.9 & 543 & 23 \\
\hline & & $\begin{array}{l}\text { Moist evergreen } \\
\text { forest on hills } \\
\text { and plateaus } \\
\text { with ferralitic soil }\end{array}$ & High forest & 76.4 & 194 & 10 \\
\hline & $\begin{array}{l}\text { Degraded natural } \\
\text { environment }\end{array}$ & $\begin{array}{l}\text { Degraded marshy } \\
\text { or flooded forest }\end{array}$ & & 80.0 & 18 & 1 \\
\hline
\end{tabular}


Table 5: Averaged sensitivities obtained with 10-fold cross validation, for land cover/use classes associated with "high" sensitivity values (greater than $80 \%$ ), total number of positive examples and number of induced rules for each class, by taking into account the whole dataset as learning set.

\begin{tabular}{|c|c|c|c|c|c|c|}
\hline 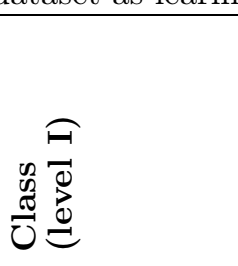 & 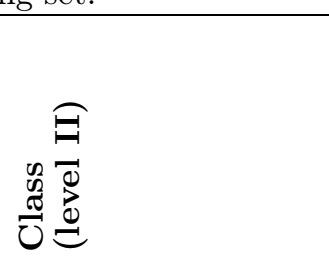 & 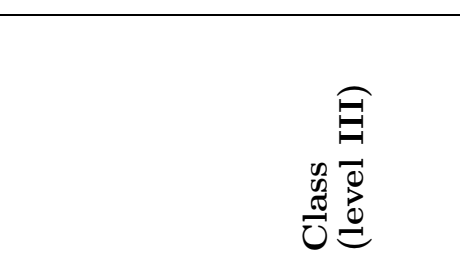 & & 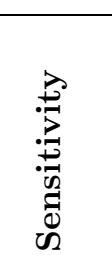 & 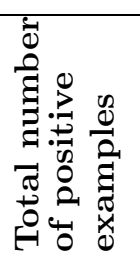 & 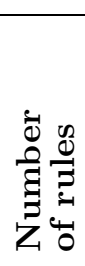 \\
\hline \multirow{5}{*}{$\begin{array}{l}\text { Artificial } \\
\text { Territories }\end{array}$} & \multirow[t]{4}{*}{ Urbanized areas } & Continuous urban area & & 93.0 & 42 & 3 \\
\hline & & Discontinuous urban area & & 87.9 & 166 & 5 \\
\hline & & Isolated building & & 95.3 & 1191 & 8 \\
\hline & & Multidisciplinary habitat & & 94.4 & 552 & 2 \\
\hline & Industrial zone & Airport & & 100.0 & 12 & 1 \\
\hline \multirow{2}{*}{$\begin{array}{l}\text { Agricultural } \\
\text { Territories }\end{array}$} & $\begin{array}{l}\text { Permanent } \\
\text { cultivation }\end{array}$ & Fruit orchards & & 87.1 & 259 & 1 \\
\hline & $\begin{array}{l}\text { Heterogeneous } \\
\text { agricultural areas }\end{array}$ & $\begin{array}{l}\text { Fragmented/complex } \\
\text { cropping systems } \\
\text { (slash \& burn) }\end{array}$ & & 81.9 & 814 & 6 \\
\hline \multirow{9}{*}{$\begin{array}{l}\text { Forest and } \\
\text { semi-natural } \\
\text { area }\end{array}$} & \multirow[t]{5}{*}{ Forest } & Forest plantation & & 81.7 & 21 & 1 \\
\hline & & $\begin{array}{l}\text { Moist evergreen forest } \\
\text { of the mainland } \\
\text { coastal plains }\end{array}$ & $\begin{array}{l}\text { Forest on } \\
\text { sandy cord }\end{array}$ & 82.0 & 49 & 3 \\
\hline & & $\begin{array}{l}\text { Moist evergreen forest } \\
\text { on hills and plateaus } \\
\text { with ferralitic soil }\end{array}$ & Low forest & 98.0 & 58 & 1 \\
\hline & & Marshy or flooded forest & & 91.7 & 288 & 5 \\
\hline & & Mangrove & & 93.0 & 259 & 16 \\
\hline & \multirow[t]{2}{*}{$\begin{array}{l}\text { Shrubby } \\
\text { environment }\end{array}$} & Dry savannah & & 93.9 & 164 & 1 \\
\hline & & Flooded savannah & & 92.0 & 98 & 3 \\
\hline & $\begin{array}{l}\text { Open space with } \\
\text { some/no vegetation }\end{array}$ & $\begin{array}{l}\text { Bare rocks, } \\
\text { Rock savannah }\end{array}$ & & 100.0 & 6 & 1 \\
\hline & $\begin{array}{l}\text { Degraded natural } \\
\text { environment }\end{array}$ & $\begin{array}{l}\text { Forest and shrubs } \\
\text { in mutation }\end{array}$ & & 100.0 & 602 & 18 \\
\hline \multirow{3}{*}{ Wet areas } & \multirow[t]{2}{*}{ Lower wet areas } & $\begin{array}{l}\text { Interior marshes and } \\
\text { wooded swamps }\end{array}$ & & 92.6 & 163 & 4 \\
\hline & & Riparian swamp & & 100.0 & 38 & 1 \\
\hline & Marin Wetland & Tidal marsh & & 88.9 & 9 & 1 \\
\hline \multirow{2}{*}{ Water surface } & \multirow[t]{2}{*}{ Continental water } & Pisciculture and other basins & & 85.0 & 18 & 1 \\
\hline & & Natural water surface & & 100.0 & 4 & 1 \\
\hline
\end{tabular}


Table 6 summarizes the results for overall accuracy and Kappa Index. Overall accuracy values varied from $82.4 \%$ to $87.3 \%$ with an average of $84.6 \%$. Kappa Index varied from 0.69 to 0.77 with an average value of 0.70 .

Table 6: Kappa and overall accuracy values.

\begin{tabular}{lcccccccccc}
\hline \hline Test set & 1 & 2 & 3 & 4 & 5 & 6 & 7 & 8 & 9 & 10 \\
\hline \hline \multirow{2}{*}{ Kappa } & 0.69 & 0.67 & 0.74 & 0.71 & 0.75 & 0.68 & 0.69 & 0.73 & 0.60 & 0.77 \\
\cline { 2 - 9 } & \multicolumn{8}{c}{0.70 (average) } \\
\hline \begin{tabular}{l} 
Overall $\begin{array}{l}\text { accuracy } \\
(\%)\end{array}$ \\
\cline { 2 - 9 }
\end{tabular} & 83.0 & 87.3 & 84.3 & 85.0 & 84.3 & 85.1 & 84.1 & 83.1 & 87.2 & 82.4 \\
\hline \hline
\end{tabular}

\subsection{Map of prediction errors}

By regrouping the results for the 10 test sets, it was possible to construct a prediction map for the year of interest (2008 in this case). Figure 3 is the spatial representation of such prediction errors, highlighting that the errors are not homogeneously distributed in space, two error clusters being present at the extreme west and at the center of the territory. 


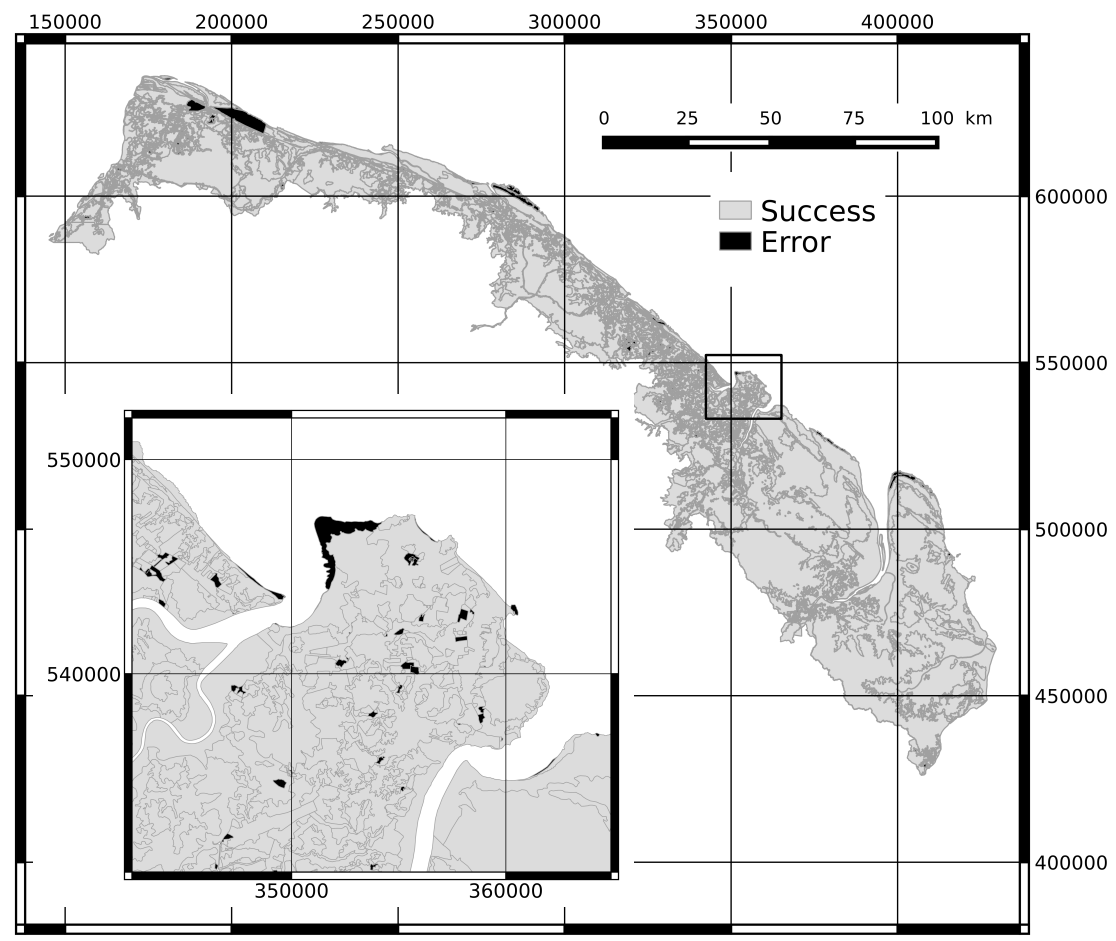

Figure 3: Map of prediction errors (geographic coordinate system: WGS84 / UTM zone 22N). Map at the top represents French Guiana coastline; Map in the inset zooms in on the "Cayenne Island".

378

\section{Discussion}

From a qualitative point of view, induced rules are consistent with the observed environmental features and dynamics of the study area. Moreover, they are provided in an expressive formalism, and are easily understandable and interpretable by non-experts, as they can be expressed in natural language. However, some rules covered very few (2 or 3) positive examples, whereas the total number of positive examples for the associated classes was 
large (see rule (3) in paragraph 4.1 for example). Such rules were consequently very specific and did not represent a significant knowledge within the application domain.

The predicates south, north, east and west did not appear in the rules, showing that such predicates were not pertinent for object discrimination, and that characterization of the objects should make better use of expert knowledge. In particular, domain ontologies could guide the learning process by identifying the predicates and the learning constraints to use.

Whereas the maximum premise length was set to 5 , induced rules comprised at most 4 literals. For some classes, this can be explained by the fact that the upper bound on the nodes to be explored when searching for an acceptable clause (i.e., 5000, the default value) was reached and that Aleph stopped before having scanned all the search space.

When considering the sensitivity values, we noticed that classes associated with very high sensitivity (Table 5) underwent no or slow changes with time, as the knowledge of the land cover type at one time in the past defined for a large part the land cover type at present and in the future. It is the case for very anthropogenic land use classes such as Airport and Isolated buildings or for very stable natural land cover types that cannot be exploited by humans due to natural and/or legal constraints, such as Bare rocks, Rock savannah, Riparian swamp, or Natural water bodies. Instead, classes associated with low sensitivity values (Table 3 ) seemed to correspond to continually and rapidly shifting land cover/use types. It is more specifically the case for the following classes: Beach, mud bank or dune, which is a class associated with a highly dynamic environment (Anthony et al., 2010); Construction sites and 
Territories occupied mainly by agriculture with presence of vegetation, which is a complex class including traditional itinerant slash and burn activities that consist in cultivating an area and then letting the natural vegetation to regenerate. This seems to indicate that the information provided by the land cover/use maps is insufficient in terms of anteriority and/or time resolution for these classes. However, prediction performances could be improved. In fact, background knowledge can be enriched by adding predicates, possibly evaluated from complementary geographic information layers (digital elevation model, soil map, etc.). As already mentioned, the choice of these complementary object features can be guided by expert knowledge, notably through domain ontologies. Better performances could also be obtained by implementing different learning and classification strategies: in our case, $a$ priori known classes at year $y_{0}$ could be exploited to learn more efficient rules. These classes should be the most stable in time and the easiest to identify (e.g. River, Continuous urban area, Airport, etc.). An iterative learning-classification strategy could also be implemented, by: i) first learning and classifying classes associated with high-performance predictions (e.g. Forest and shrubs in mutation, see Table 5); ii) then using the prediction to enrich the background knowledge of other classes; iii) learning-classifying these classes; iv) repeating the procedure until all classes are predicted. However, the number of strategies is such that we must rely on objective criteria and/or intensive simulations to determine the most appropriate one. Nevertheless, our method gave good results globally. In fact, in addition to the excellent sensitivity and specificity values returned by the procedure, the Kappa Index and overall accuracy values were high. According to the Kappa 
interpretation table by (Landis and Koch, 1977), these values denote "strong agreement" between predicted and actual classes.

The spatial representation of the prediction errors highlighted that the errors are not homogeneously distributed in space. Except for the errors already discussed and associated with highly dynamic environmental processes, essentially distributed along the ocean (e.g., Beach, mud bank or dune), two error clusters were identified at the extreme west and at the center of the territory. Understanding such errors will require further investigation, but they may be explained by the presence of errors in the initial maps. Consequently, we suggest that the present work can also be a tool to guide the validation of the existing maps.

Inductive Logic Programming is devoted to symbolic data. The management of numeric information by ILP constitutes a specific research field, which is beyond the scope of this paper. However, several simple solutions exist in order to code the numeric data into symbolic ones. In fact, the domain of values of a numeric variables can be categorized by means of crisp or fuzzy modalities. We propose here to code the numeric information by means of inequalities taking into account quantiles of the numeric variable empirical distribution. This enables Aleph to manage numeric information in a manner comparable to the Confidence-based Concept Discovery $\left(\mathrm{C}^{2} \mathrm{D}\right)$ ILP system (Kavurucu et al., 2011). This solution seems to offer a good compromise between information loss and generalization capacity, by allowing the system to automatically discover significant value intervals (see rule (3) in the Results section).

Finally, the method proposed here does not consider the image processing 
step devoted to the delimitation of the regions of the image that define the objects. It only considers the labeling (or classification) of the regions. This implies: that the partitioning of the image into regions is performed beforehand, by means of any methods including fully manual ones (photo-interpretation) or automatic image segmentation algorithms; that the new objects, which labels have to be predicted, have been delimited by the method that produced the objects used for the learning task of the classification rules.

\section{Conclusion}

This article describes an approach inducing classification rules to automatically label regions of remote sensing images in order to design land cover/use maps. Automatic extraction of structural knowledge using Inductive Logic Programming was implemented and new examples were classified to a unique class by means of the Multi-class Rule Set Intersection method. The proposed methodology was then applied to update the land cover/use of the French Guiana coastline and evaluated thoroughly.

We show that the induced rules provide knowledge on structural aspects. The quantitative evaluation of our method demonstrated promising results, allowing to offer automatic updating of the land cover/use information in the study region and significant support to the operators in charge of such updating. In particular, our approach could provide valuable assistance to operators using object-based image analysis. In fact, such image analysis approach allows integrating high level symbolic knowledge concerning spatial relations in the classification process. However, to our knowledge, it does not offer any support to the operators in order to define efficient and general 
rules that take into account such knowledge.

Our future work should include guiding the learning process by specifying background knowledge through domain ontologies (related to remote sensing, images, environment, etc.). In return, the induced rules would contribute to enrich the ontologies.

\section{Acknowledgements}

This work has been performed within the framework of the project CARTAMSAT (CARtographie du Territoire AMazonien: des Satellites aux AcTeurs - Dynamic mapping of Amazonian Territories: from Satellites to Actors) which is funded by the European Regional Development Funds (FEDER) for French Guiana: agreement number 30492. The work was also supported by the GEOSUD EQUIPEX Project.

\section{References}

Abudawood, T., Flach, P.A., 2011. Learning multi-class theories in ilp, in: Proceedings of the 20th international conference on Inductive logic programming, Springer-Verlag, Berlin, Heidelberg. pp. 6-13.

Andres, S., Arvor, D., Pierkot, C., 2012. Towards an ontological approach for classifying remote sensing images, in: Signal Image Technology and Internet Based Systems (SITIS), 2012 Eighth International Conference on, pp. 825-832.

Anthony, E.J., Gardel, A., Gratiot, N., Proisy, C., Allison, M.A., Dolique, F., Fromard, F., 2010. The amazon-influenced muddy coast of south america: 
A review of mud-bank-shoreline interactions. Earth-Science Reviews 103, $99-121$.

Blaschke, T., 2010. Object based image analysis for remote sensing. ISPRS Journal of Photogrammetry and Remote Sensing 65, 2-16.

Blockeel, H., Dzeroski, S., Kompare, B., Kramer, S., Pfahringer, B., Laer, W.V., 2004. Experiments in predicting biodegradability. Applied Artificial Intelligence 18(2), 157-181.

Chelghoum, N., Zeitouni, K., Laugier, T., Fiandrino, A., Loubersac, L., 2006. Fouille de donnees spatiales - approche basee sur la programmation logique inductive, in: 6emes Journées d'Extraction et de Gestion des Connaissances, Edition CEPADUES. pp. 529-540.

Cohen, J., 1960. A coefficient of agreement for nominal scales. Educational and Psychological Measurement 20, 37-46.

Cordier, M.O., 2005. Sacadeau: A decision-aid system to improve streamwater quality. ERCIM News 61, 37-38.

Durand, N., Derivaux, S., Forestier, G., Wemmert, C., Gançarski, P., Boussaid, O., Puissant, A., 2007. Ontology-based object recognition for remote sensing image interpretation, in: Proceedings of the 19th IEEE International Conference on Tools with Artificial Intelligence - Volume 01, IEEE Computer Society, Washington, DC, USA. pp. 472-479.

Fonseca, N.A., Silva, F., Camacho, R., 2006. April - an inductive logic programming system, in: JELIA, pp. 481-484. 
Forestier, G., Puissant, A., Wemmert, C., Gançarski, P., 2012. Knowledgebased region labeling for remote sensing image interpretation. Computers, Environment and Urban Systems 36, 470 - 480.

Fromont, E., Cordier, M.O., Quiniou, R., 2005. Extraction de connaissances provenant de données multisources pour la caractérisation d'arythmies cardiaques, in: Fouille de données complexes. Cepaduès. volume RNTI-E-4 of Revue des Nouvelles Technologies de l'Information, pp. 25-45.

Goodacre, J., 1996. Inductive Learning of Chess Rules Using Progol. Oxford University.

Hudelot, C., Atif, J., Bloch, I., 2008. Fuzzy spatial relation ontology for image interpretation. Fuzzy Sets and Systems 159, 1929-1951.

Kavurucu, Y., Senkul, P., Toroslu, I., 2011. A comparative study on ilpbased concept discovery systems. Expert Systems with Applications 38, $11598-11607$.

Landis, J.R., Koch, G.G., 1977. The measurement of observer agreement for categorical data. Biometrics 33, pp. 159-174.

Lavrac, N., Dzeroski, S., 1994. Inductive Logic Programming: Techniques and Applications. Ellis Horwood.

Luu, T.D., Rusu, A., Walter, V., Linard, B., Poidevin, L., Ripp, R., Muller, L.M.J., Raffelsberger, W., Wicker, N., Lecompte, O., Thompson, J.D., Poch, O., Nguyen, H., 2012. Kd4v: Comprehensible knowledge discovery system for missense variant. Nucleic Acids Research 40, W71-W75. 
Malerba, D., Esposito, F., Lanza, A., Lisi, F.A., Appice, A., 2003. Empowering a gis with inductive learning capabilities: the case of ingens. Computers, Environment and Urban Systems 27, 265 - 281.

GRASS Development Team, 1999-2012. Welcome to grass gis. http://grass.fbk.eu/.

Michalski, R.S., 1983. Machine learning: An artificial Intelligence Approach. TIOGA Publishing Co.. chapter a theory and methodology of inductive learning. pp. 110-161.

Muggleton, S., 1991. Inductive logic programming. New Generation Computing 8, 295-318.

Muggleton, S., 1995. Inverse entailment and progol. New Generation Computing 13, 245-286.

Santos, J., Nassif, H., Page, D., Muggleton, S., Sternberg, M., 2012. Automated identification of protein-ligand interaction features using inductive logic programming: A hexose binding case study. BMC Bioinformatics 13, 162.

Srinivasan, A., 2007. The aleph manual. http://www.cs.ox.ac.uk/activities/ machlearn/Aleph/aleph.html.

Srinivasan, A., Muggleton, S., Sternberg, M.J.E., King, R.D., 1996. Theories for mutagenicity: A study in first-order and feature-based induction. Artificial Intelligence 85, 277-299. 
572 Suzuki, H., Matsakis, P., Andrefouet, S., Desachy, J., 2001. Satellite image 573 classification using expert structural knowledge: A method based on fuzzy 574 partition computation and simulated annealing, in: IAMG 2001, pp. 251 $575-268$.

Vaz, D., Costa, V.S., Ferreira, M., 2010. Fire! firing inductive rules from economic geography for fire risk detection, in: ILP, pp. 238-252.

Vaz, D., Ferreira, M., Lopes, R., 2007. Spatial-yap: a logic-based geographic information system, in: Proceedings of the 23rd international conference on Logic programming, Springer-Verlag, Berlin, Heidelberg. pp. 195-208.

Zaiche, L., Smith, A., 2011. $50 \%$ de satellites en plus à lancer sur les dix prochaines années. http://www . perspectives-spatiales.com/sites/perspectives-spatiales.com /files/50\%25 de satellites en plus sur la prochaine décennie.pdf. 